\title{
PENINGKATAN KINERJA MANAJEMEN RANTAI PASOK TUNA SEGAR DI PPS NIZAM ZACHMAN JAKARTA (PPSNZJ)
}

\author{
Supply Chain Management Performance Improvment for Fresh Tuna's Product in PPSNZJ
}

Oleh:

Muhamad Yogi Prayoga ${ }^{1^{*}}$, Budhi Hascaryo Iskandar ${ }^{1}$, Sugeng Hari Wisudo ${ }^{1}$

${ }^{1}$ Departemen PSP, FPIK IPB

*Korespondensi: myogip@gmail.com

\begin{abstract}
ABSTRAK
Tujuan dari penelitian ini adalah menganalisis pengelolaan, distribusi serta faktor-faktor yang berpengaruh dalam rantai pasok tuna segar di Pelabuhan Perikanan Samudra Nizam Zachman Jakarta (PPSNZJ)(i), mengukur kinerja dan merumuskan rekomendasi langkah-langkah peningkatan peningkatan kinerja rantai pasok yang lebih efektif dan efisien(ii). Metodelogi yang digunakan dalam penelitian adalah deskriptif analitik Asian Productivity Organization (APO), Supply Chain Operations Reference (SCOR), dan Strengths Weaknesses Oportunities Threats (SWOT). Pengelolaan rantai pasok ikan tuna segar mempunyai model yang menempatkan nelayan sebagai produsen utama. Pasar utama produk tuna segar yang didaratkan di PPSNZJ adalah negara jepang dengan mutu tuna A+ (sangat istimewa) dan A (istimewa). Hasil dari analisis adalah masih adanya permasalahan dan tantangan dalam proses pengelolaan tuna segar menjadi lebih efektif dan efisien. Strategi yang dihasilkan adalah untuk dijadikan rekomendasi untuk rantai pasok di PPSNJZ, diantaranya mempererat kemitraan antar patner, optimalisasi institusi terkait, dan pemusatan informasi pemasaran. Hasil analisis peningkatan kinerja rantai pasok tuna segar di PPSNJZ diutamakan pada beberapa matrik yang diutamakan pada reabilitas, fleksibilitas, dan responsivitas. Rekomendasi pengelolaan rantai pasok yang dirancang untuk peningkatkan kinerja yang mampu menangani $30 \%$ matrik pemenuhan pemesanan sempurna, $70 \%$ untuk metrik penyesuian rantai pasok atas, pengurangan 7 hari untuk metrik siklus pemenuhan pesanan, dan 3 hari untuk metrik fleksibilitas rantai pasok atas.
\end{abstract}

Kata kunci: Pengelolaam rantai pasok, PPSNZJ, SCOR, Tuna segar.

\begin{abstract}
The purposes of this research were (i) to analyze the supply chain management of fresh tuna, distribution, and the factors that influence the supply chain of fresh tuna at the Oceanic Port Fisheries of NizamZachman Jakarta (PPSNZJ), (ii) to measure the performance of the supply chain development of fresh tuna, and to formulate the recommendations supply chain performance improvement that more effective and efficient. The method was used in this research aredescriptiveanalysis, Supply Chain Operations Reference (SCOR), Asian Productivity Organization (APO), and Strength Weakness Oportunity Treat (SWOT). The management of fresh tuna supply chain has one model that puts the fisherman as the main producer. The main market of fresh tuna that was landed at PPSNZJ is Japan which has $A+$ (very special) and A (special) quality of product. The result showed that were problems and challenges to make the procces and the mechanism of the fresh tuna supply chain became more efective and efficient. The strategy that produced will serve as recommendation for the fresh tuna supply chain in PPSNZJ, like as making a stronger relationship and partnership among partner, optimizing the related institutions, and centralizing the information of marketing. Supply chain performance improvement of fresh tuna at PPSNZJ preferably in several matrices which include reliability, flexibility, and responsiveness. The recommendation of fresh tuna supply chain
\end{abstract}


management was designed should has capability in handle $30 \%$ of perfect order fulfillment metric and $70 \%$ of correlation supply chain overmetric, where was reduced the perfect order fulfillment metric along 7 days and correlation overmetric along 3 days.

Keywords: Fresh tuna, PPSNZJ, SCOR, Supply chain management.

\section{PENDAHULUAN}

Permintaan terhadap hasil tangkapan ikan tuna segar dari nelayan sebagai komoditas dengan nilai ekonomis tinggi semakin meningkat setiap tahunnya. Hal tersebut terjadi karena meningkatnya minat masyarakat terhadap produk hasil tangkapan nelayan. Peran pelabuhan perikanan sebagai sentral pendaratan ikan sangat pening dalam memenuhi permintaan masyarakat dan industri. Salah satu pelabuhan perikanan dengan produksi yang paling tinggi di Indonesia adalah Pelabuhan Perikanan Samudra Nizam Zachman Jakarta (PPSNZJ).

Pengelolaan rantai pasok pada perikanan komoditas ikan tuna segar sangat diperlukan, karena komoditas tersebut memiliki nilai ekonomis, permintaan tinggi, dan manfaat yang tinggi bagi nelayan dan masyarakat. Perlunya pengelolaan rantai pasok yang tepat pada komoditas perikanan tuna di PPSNZJ untuk menambah nilai, menjaga stok dan kualitas, serta dapat dengan mudah dijangkau oleh masyarakat. Produksi hasil tangkapan di suatu pelabuahan perikanan sangat dipengaruhi oleh permintaan terhadap suatu komoditas.

Peningkatan permintaan tersebut mempengaruhi total produksi di PPSNZJ priode tahun 2010 sampai dengan 2014 menunjukan kecendrungan peningkatan. Secara berturut-turut peningkatan produksi pada tahun 2011 sampai dengan tahun 2014 adalah sebesar $0.54 \% ; 14.62 \% ; 17.67 \%$; dan $7.01 \%$. Peningkatan total produksi tersebut menunjukan bahwa kualitas pendaratan produksi ikan semakin baik. Hal tersebut menyebabkan peningkatan total produksi ikan di PPSNZJ adalah meningkatnya frekuensi kapal yang melakukan kegiatan bongkar HTI, PPSNZJ (2015).
Pengelolaan fasilitas dan manajemen transportasi ikan yang efektif dan efisien pada rantai pasok tuna segar dapat meningkatkan kinerja, efisien waktu dan tenaga, menekan biaya operasional, kualitas ikan yang tetap terjaga, serta jangkauan distribusi yang luas. Manajemen Rantai Pasok (Supply Chain) merupakan serangkaian pendekatan yang diterapkan untuk mengintegrasikan pemasok, pengusaha, gudang (warehouse) dan tempat penyimpanan lainnya secara efisien sehingga produk dapat dihasilkan dan didistribusikan kepada konsumen dengan kuantitas, kualitas, lokasi, dan waktu yang tepat untuk memperkecil biaya dan memuaskan kebutuhan konsumen (David et al., 2000 dalam Indrajit dan Djokopranoto, 2002).

Tranportasi ikan dalam sistem rantai pasok merupakan proses distribusi dalam rangka menambah nilai ekonomis dan manfaat hasil tangkapan ikan nelayan menuju tempat pemasaran ikan. Lokasi daerah penagkapan ikan (DPI) dengan daerah pamasaran biasanya berjauhan sehingga dibutuhkan manajemen pengiriman yang baik agar kualitas ikan tetap baik sampai tempat tujuan. Ikan tuna segar adalah komoditas ekspor dengan nilai ekonomis tinggi, mengalami proses distribusi dan transportasi dengan antar negara yang jaraknya sangat jauh.

Penelitian ini akan mengkaji kinerja pengelolaan rantai pasok perikanan tuna segar dengan mengacu pada statistik produksi, permintaan, distribusi, dan pemasaran hasil tangkapan. Merumuskan strategi pengelolaan yang efektif untuk meningkatkan kinerja rantai pasok perikanan. Hal ini dimaksudkan agar sistem di dalam rantai yang menghubungkan perusahaan dengan supplier mampu bekerja dengan optimal dan tujuan perusahaan dapat tercapai. Tujuan dari penelitian ini adalah sebagai berikut :

1. Menganalisa pengelolaan, fasilitas pendukung dan distribusi dan faktor- 
faktor yang berpengaruh dalam rantai pasok di PPS Nizam Zachman.

2. Mengukur kinerja dan merumuskan rekomendasi langkah-langkah rantai pasok perikanan tuna segar.

\section{METODELOGI PENELITIAN}

\section{Waktu dan Tempat Penelitian}

Penelitian ini dilakukan di Pelabuhan Perikanan Samudra Nizam Zachman, Jakarta. Lokasi penelitian difokuskan pada beberapa dramaga transit pelabuhan perikanan, tempat pendaratan, dan perusahaan pengolahan ikan. Penelitian ini dilakukan pada bulan Juni hingga bulan September tahun 2015.

\section{Metode Pendekatan Masalah}

Ikan tuna segar sebagai komoditas bernilai tinggi memilki potensi pengembangan pasar yang sangat baik di dalam maupun luar negri. Hal tersebut perlu didukung dengan daya saing yang baik pada pengelolaan rantai pasoknya. Menurut Marimin dan Maghfirah (2007), usaha peningkatan daya saing melalui SCM (Supply Chain Management) penting untuk mengatasi bebagai faktor yang menjadi permasalahan yang terjadi dilapangan seperti kerjasama yang belum sinergis antar pelaku pengusaha, aktivitas perdagangan tidak terpadu, pengelolaan rantai pasok yang tidak efisien, sehingga kontinuitas ketersediaan tuna segar menjadi kurang stabil.

Ikan tuna yang dikaji adalah jenis tuna sirip kuning/yellow fin tuna, tuna mata besar/big eye tuna, dan tuna albakor. Hal tersebut bertujuan agar pengkajian dapat lebih fokus dan terarah pada komoditas ikan tuna yang di daratkan di PPSNZJ. Kajian penerapan manajemen rantai pasok ikan tuna dapat menggambarkan komoditas penting ikan lainnya, sehingga jika pengelolaan rantai pasok tuna segar bisa berjalan dengan baik, dapat mendorong terbentuknya pengelolaan rantai pasok ikan secara keseluruhan.

\section{Metode Pengolahan Data}

Data yang dikumpulkan terdiri dari data primer dan sekunder. Data primer diperoleh dari hasil wawancara mendalam terhadap beberapa stakeholder terkait kegiatan rantai pasok ikan tuna di PPSNZJ. Beberapa aspek yang ditanyakan pada wawancara mendalam tersebut yaitu terkait produksi ikan, distribusi ikan, biaya produksi dan distribusi, dan kelembagaan. Selain itu, melalui wawancara mendalam tersebut juga dicari informasi terkait solusi yang diharapkan oleh stakeholder pada permasalahan yang ada. Jumlah responden pada tahap ini adalah 8 perusahaan, 3 pengelola dramaga transit, serta 5 orang dari syahbandar dan UPT pelabuhan. Data sekunder dikumpulksn melalui studi literatur yang bersumber dari laporan yang dikeluarkan oleh PPSNZJ Jakarta, jurnal dari website, buku-buku relevan, serta sumber-sumber lainnya.

\section{Analisis Data}

Penelitian ini menggunakan metode deskriptif analitik untuk mengolah data hasil wawancara yang diperoleh, dimana tahapan proses SCOR (Supply Chain Operations Reference) digunakan sebagai analisis data. Berikut merupakan analisis data yang dilakukan pada penelitian ini, Kerangka pengkajian pengembangan rantai pasok ikan tuna segar PPSNZJ menggunakan pengembangan Asian Productivity Organization (APO) yang telah dimodifikasi oleh Van Der Vorst (2006), yang meliputi enam aspek kajian yaitu sasaran rantai pasok(i), struktur rantai pasok(ii), sumber daya(iii), manajemen rantai(iv), proses bisnis rantai(v), dan kinerja rantai pasok(vi) (Marimin dan Nurul Magfirah 2007).

Upaya peningkatan kinerja ditunangkan dalam bentuk strategi. Strategi pengembangan rantai pasok menggunakan metode SWOT (Strengths, Weaknessea, Oportunities, Threats). Hasil dari analisis tersebut diharapkan mengurangi inefisiensi yang masih terjadi di lapangan, peluang usaha dapat tergali dan terproses dengan baik melalui pemanfaatan sumber daya sarana pelabuhan perikanan secara optimal dan melalui penerapan pengelolaan rantai pasik yang lebih efektif dan efesien dapat menurunkan cost yang selama 
yang dikeluhkan banyak pengusaha dan konsumen.

\section{HASIL DAN PEMBAHASAN}

\section{Kondisi Pelabuhan Perikanan Samudera Nizam Zachman Jakarta}

PPSNZJ adalah pelabuhan perikanan terbesar indonesia terletak di wilayah Teluk Jakarta pada 6'5'50" - 6'0" LS dan 10647'10" - 106 48'19" BT. Luas pelabuhan sebesar 110 Ha yang terdiri dari $40 \mathrm{Ha}$ kolam pelabuhan dan 70 Ha adalah daratan yang merupkan hasil reklamasi(PPSNZJ, 2015). Wilayah darat PPSNZJ meliputi kawasan industri pengolahan, perkantoran UPT dan PERUM, serta dramaga tambat labuh kapal. Kawasan Industri pengolahan ikan dan coldstroge mendominasi bagian daratan dari PPSNZJ.

Total produksi ikan PPSNZJ pada tahun 2015 adalah sebesar 187.520 ton/tahun atau 513,8 ton/hari. Produksi ikan sebanyak 99.672 ton atau 53\% masuk ke PPSNZJ masuk lewat jalur darat, sedangkan ikan yang masuk dari hasil laut adalah sebesar 87.848 ton atau $47 \%$ dari total produksi. Dominasi pasokan hasil tangkapan ikan (HTI) yang dikirim dari jalur darat disebabkan karena PPSNZJ sebagai pusat pendaratan ikan di Indonesia dengan permintaan HTI yang paling tinggi, untuk tujuan pemasaran lokal maupun ekspor. Banyaknya wilayah pemasok HTI disekitar wilayah Pulau Jawa dan Bali seperti PPN Palabuhan Ratu, PPN Benoa, PPN Sendang Biru, PPN Brondong, PPS Cilacap, dan Indonesia timur yang didaratkan di Surabaya dan didistribusikan melalui jalur darat.

Komoditas HTI unggulan yang didaratkan PPSNZJ adalah ikan tuna dan Jenis tangkapan tuna yang didaratkan di Pelabuhan PPSNZJ adalah 24,2\% . Hasil tangkapan paling tinggi dan memiliki nilai ekonomis yang penting adalah ikan tuna sirip kuning 13,6\% tuna mata besar 9,7\%, dan tuna albakor sebanyak 0,9. cakalang. Komposisi hasil tangkapan ikan di PPSNZJ dapat ditampilkan pada Gambar 1.

Tujuan pemasaran HTI di PPSNZJ didominasi oleh pangsa pasar ekspor sebesar 123.424 ton atau $50.5 \%$. Hal tersebut terjadi karena banyaknya industri pengolahan ikan di PPSNZJ yang pasar utama produknya untuk

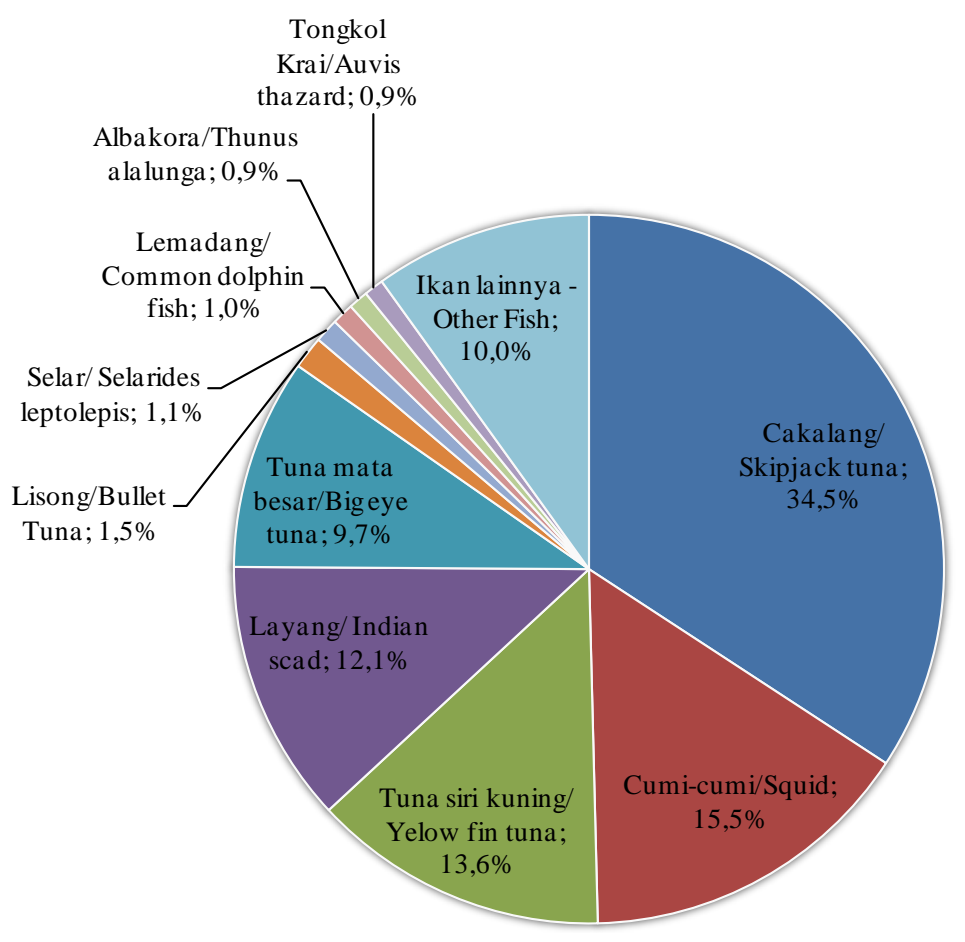

Sumber PPSNZJ (2015)

Gambar 1 Komposisi hasil tangkapan PPSNZJ 


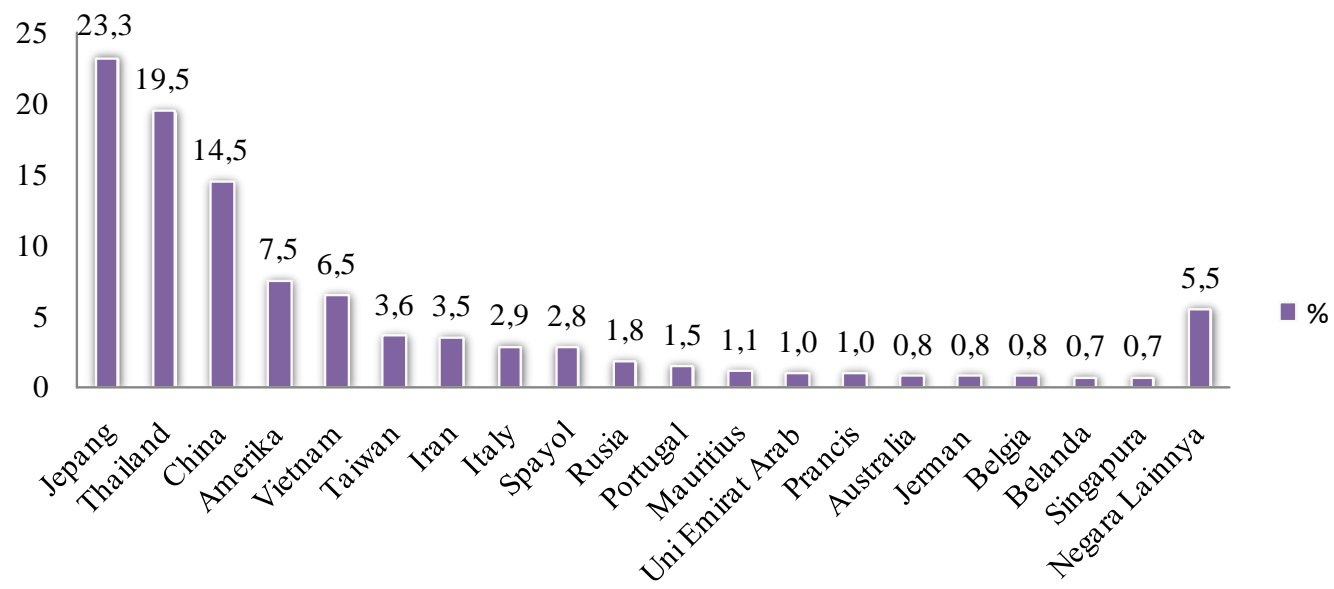

Sumber PPSNZJ (2015)

Gambar 2 Grafik presentase distribusi HTI ekspor

diekspor ke wilayah Uni Eropa, Asia (Jepang, Thailand dan Cina), serta Amerika Serikat. Pemasaran hasil tangkapan regional dan lokal tidak berbeda jauh, HTI lokal yaitu sebesar 121216,7 ton atau $49,4 \%$ dari total produk hasil tangkapan di PPSNZJ. HTI tujuan distribusi ekspor ditampilkan di Gambar 2.

Hasil tangkapan tujuan ekspor PPSNZJ didominasi oleh produk tuna berupa fresh tuna, frozen tuna, loin, saku, dan kaleng. Produk tuna dengan kualitas terbaik (grade A+ dan A) langsung diekspor ke Jepang dalam bentuk utuh / fresh tuna hari itu juga, total ekspor fresh tuna ke Jepang mencapai 23,5\% pertahun dari total/tahun. Untuk produk HTI olahan tuna seperti loin, saku, dan kaleng sebagain besar di ekspor ke Amerika Serikat dan Uni Eropa. China dan Thailand merupakan negara pasar ekspor produk ikan karang dan udang yang didaratkan serta diolah di PPSNZJ.

\section{Analisa Model Rantai Pasok Tuna Segar di PPSNZJ}

\section{A. Struktur Rantai Pasok}

Aliran rantai pasok tuna segar di PPSNZJ sangat dipernguruhi oleh tingkat mutu tuna yang didaratkan, pihak yang terlibat dalam rantai pasok, aturan main yang berlaku di rantai pasok, serta tujuan pemasaran. Hal yang paling dominan mempengaruhi rantai pasok tuna adalah kualitas dan tujuan pemasarannya.

Secara umum, aliran komoditas tuna segar tersebut terbagi ke dalam model rantai pasok tunggal. Model yang melibatkan nelayan sebagai captor (produsen tuna) dan anggota utama yang paling berperan. Model rantai pasok tuna segar dijelaskan pada Gambar 3.

Anggota primer dalam rantai pasok adalah nelayan, dramaga transit, transit pengolah, distributor, eksportir, dan perusahan pengolahan. Sedangkan anggota sekunder adalah penyedia sarana produksi seperti BBM, ransum, kapal, alat tankap dan perlengkapan lainnya yang digunakan dalam penangkpan ikan tuna.

\section{B. Sasaran Rantai Pasok}

Ikan tuna yang diperdagangkan dalam rantai pasok ini pada umumnya mempunyai kualitas sangat baik (A, A+) dengan tujuan pasar utama negara Jepang. Sedangkan untuk ikan tuna kualitas sedang (B dan C) diperdagangkan segar untuk perusahaan pengolahan lokal, atau beku untuk perusahaan lokal dan ekspor. Tuna segar umumnya

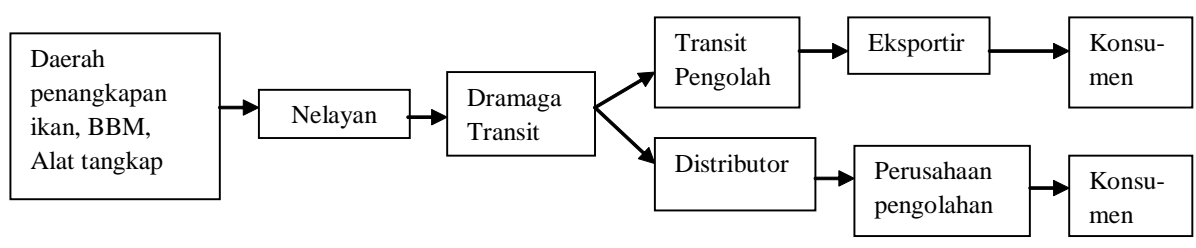

Gambar 3 Model rantai pasok tuna segar PPSNZJ 
dikonsumsi mentah (tanpa dimasak) sebagai menu restoran Jepang, seperti sashimi dan sushi.

Sasaran pasar produk tuna segar yang berkualitas tinggi meliputi restoran, perhotelan, dan masyarakat dengan ekonomi menengah ke atas. Pasar lokal rantai pasok tuna segar dengan kualitas tunggi diharapkan tidak hanya untuk komoditas ekspor, tetapi mulai diarahkan untuk pasar lokal, agar masyarakat mulai melirik ikan tuna sebagai sumber protein yang unggul.

\section{Manajemen Rantai Pasok}

Sebagian besar nelayan yang mendaratkan hasil tangkpan tuna di PPSNZJ membentuk hubungan mitra dagang tidak terikat, atau hanya sebatas langganan terhadap salah satu dramaga transit pendaratan tuna. Dramaga transit yang sering dijadikan tempat pendaratan ikan tuna adalah dramaga timur, dengan no transit 2,16,17,19, dan 20. Keberadaan dramaga transit tersebut mendorong perluasan jaringan, peningkatan posisi tawar, dan kemudahan pelaksanaan pendataan oleh pihak pelabuhan.

Tuna segar tersebut di distribusikan langsung oleh dramaga transit atau perusahaan pengolah ikan melalui ekportir yang menggunakan moda pengiriman pesawat terbang. Pengiriman tuna segar untuk pasar ekspor jepang dilakukan setiap hari kecuali hari jumat. Waktu pengiriman tuna segar untuk ekspor ke negara Jepang mengunakan jalur udara biasanya dilakukan pada jam pagi 09.00-10.00 WIB, siang 12.00-18.00 WIB, atau jam malam 20.00-21.00 WIB.

Keberadaan dramaga transit belum sepenuhnya meningkatkan posisi tawar nelayan secara keseluruhan, penyebabnya antara lain tidak adanya bentuk kerjasama yang jelas dengan dramaga transit atau perusahaan pengolahan, dan tidak adanya standar pembagaian upah yang jelas untuk nelayan ABK.

Tidak adanya ikatan kontraktual antara nelayan dengan dramaga transit di dalam rantai pasok ikan tuna segar, maka sistem transaksi yang digunakan meliputi pembayaran cash antara nelayan dengan dramaga transit, dan transfer rekening oleh pihak pelelangan/ritel di pasar tujuan (jepang). Pelelangan tuna segar diharapkan mampu mencitrakan transparansi harga dan daya saing nelayan tuna saat ini belum berjalan secara efektif karena modal dan keuntungan nelayan baru akan diberikan jika tuna yang dilelang telah terjual, sehingga mengurangi produktifitas nelayan dari segi finansial.

\section{Sumber Daya Rantai}

Indonesia merupakan negara dengan potensi tuna tertinggi di dunia dan diperhitungkan dalam bisnis tuna. data resmi FAO mencatat tahun 2014, kurang lebih 6,8 juta metrik ton tuna dan sejenis tuna ditangkap oleh banyak negara di seluruh dunia, dan Indonesia berhasil memasok lebih dari 16\% total produksi dunia dengan rata-rata produksi tuna, cakalang dan tongkol Indonesia mencapai lebih dari 1,1 juta ton/tahun. Tentunya nilai ekonomi dari perdagangan produk perikanan tuna Indonesia ini sangat besar dan menjadi peluang yang terus dimanfaatkan (Ditjen PT, 2016). Ikan tuna yang ditangkap nelayan sebagian besar dari WPP 572, WPP 573 serta Samudra Hindia.

Mengkaji potensi tuna indonesia yang demikian, maka masih berpotensi ke arah pengembangan skala industri menengah dan besar dengan visi pengembangan yang berkelanjutan dan ramah lingkungan. Fasilitas dan sumberdaya fisik di PPSNZJ dan sekitarnya seperti infrastruktur transportasi dan distribusi secara umum telah memadai. Pengiriman tuna segar menuju jepang dilakukan antara dramaga transit berkerjasama penyedia jasa pengiriman (forwarder), tidak ada keluhan yang berarti dari nelayan dan pihak dramaga terkait kondisi fisik dan pelayanan transportasi.

\section{E. Proses Bisnis Rantai Pasok}

Proses bisnis antara anggota rantai pasok tuna segar menggambarkan bagaimana mekanisme binis terjadi didalamnya. Penting untuk diketahui mengenai hubungan keterkaitan yang terjadi, serta pengaruhnya bagi kelangsungan proses bisnis. Hubungan bisnis yang terjadi yang terjadi didalam rantai 
pasok tuna segar adalah proses (Chopra dan Meindl 2004).

Tahapan proses di dalam rantai pasok dibagi kedalam beberapa rangkaian siklus. Sedangkan pada proses tarik (pull) proses dilakukan untuk merespon permintaan konsumen, kemudian pada proses dorong (push) dilakukan untuk mengantisipasi permintaan konsumen. Keuntungan dari proses pull adalah penjual dapat mengurangi biaya inventory produknya dan mengurangi produk yang menumpuk bullwhip (kelebihan stok), sedangkan pada proses push penjual berusaha menyediakan produk digudangnya guna mengantisipasi datannya pesanan dari konsumen (Marimin dan Magfiroh 2007). Terjadinya penumpukan barang berpotensi rusaknya tuna segar jika barang tersebut tidak langsung dikirim untuk dipasarkan. Proses pull dari segi biaya lebih aman dan lebih menguntungkan daripada proses push. Gambar 4 menjelaskan hubungan push/pull.

Hasil analisis deskriptif, sebagian besar proses dalam proses rantai pasok. Hal tersebut terjadi karena permintaan akan ikan tuna segar harus menyesuiakan dengan hasil tangkapan ikan nelayan yang jumlahnya tidak selalu sama dan waktu berlabuh kapal yang kurang menentu. Proses perencanaan pemasaran yang kurang kolaboratif antara nelayan, dramaga transit, dan pelelangan menyebabkan posisi tawar menawar (bergaining position) nelayan lemah dan akibatanya kemampuan untuk menentukan harga tuna menjadi lemah pula.

\section{F. Hambatan Pengembangan}

Hasil pengamatan fenomena rantai pasok tuna segar di lingkungan PPSNZJ, di dapat beberapa hambatan dalam pengembangan rantai pasok. Hambatan tersebut diantaranya pembagian hasil kepada nelayan yang masih tergolong lama yaitu selama 7 hari, biaya transportasi yang tinggi, arus informasi yang tidak terpusat, posisi tawar (bergaining position) nelayan yang masih rendah, dan dukungan kebijakan yang kurang optimal.

Hambatan tersebut diatasi dengan pendekatan menggunakan kunci sukses (key succes factor) dalam mencari solusi penyelesaian dan pengmbangan. Solusi tersebut didapatkan melalui pengkajian dari detail setiap aktivitas dalam rantai pasok tuna

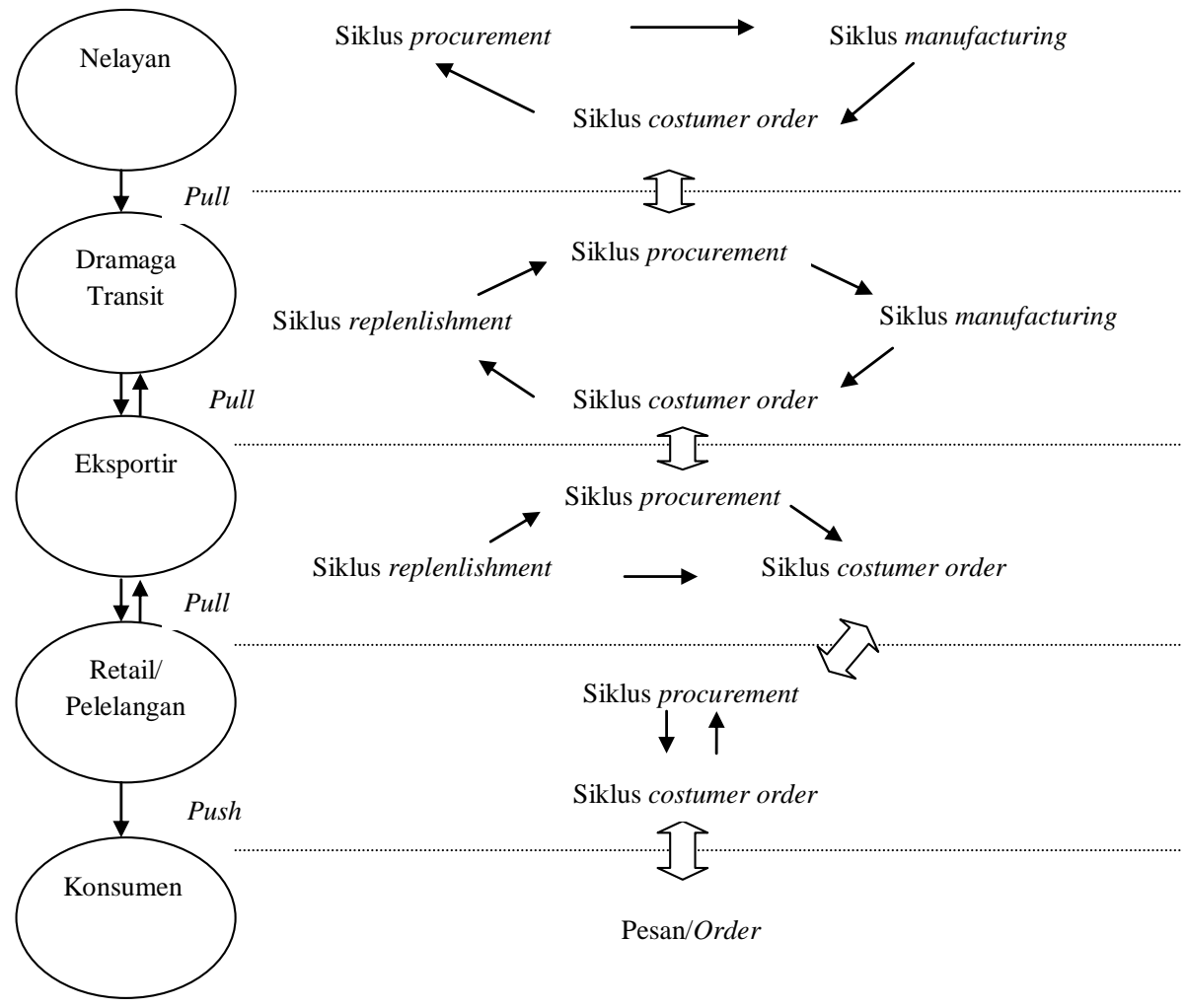

Gambar 4 Siklus proses dalam rantai pasok tuna segar PPSNZJ 


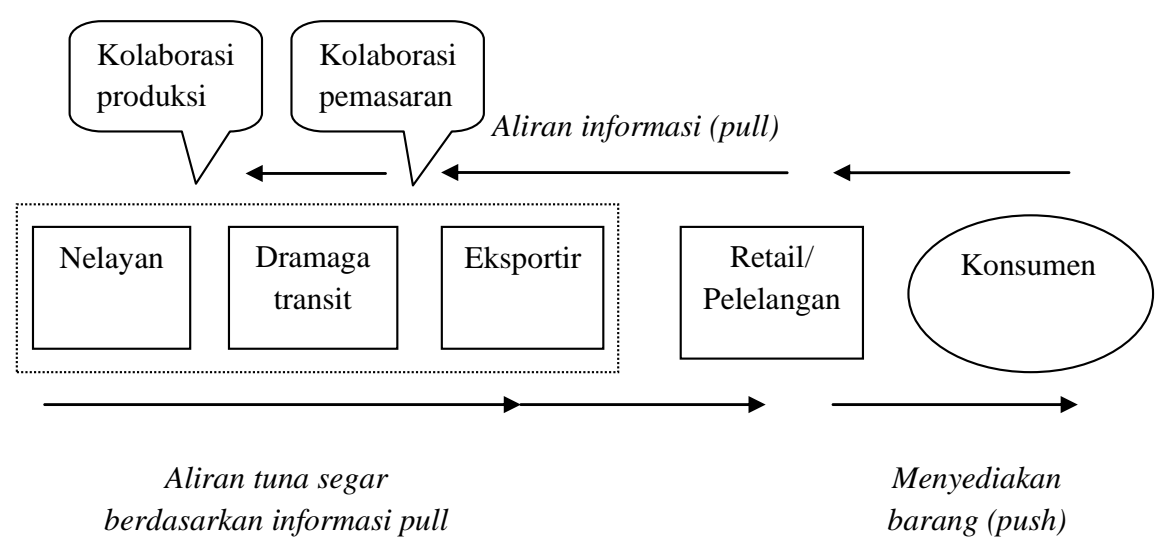

Gambar 5 Ilustrasi arus barang dan informasi dalam hubungan kolaborasi

segar. Menurut Marimin dan Syafi (2009), kunci sukses meliputi trust building (kepercayaan), koordinasi dan kerjasama, kemudahan akses pembiayaan, dan dukungan pemerintah yang baik. Kunci sukses tersebut dipertimbangkan dalam analisis SWOT serta hasilnya dimasukan pada rekomendasi rantai pasok.

\section{G. Rekomendasi}

Hal terpenting dari pengelolaan rantai pasok yang baik adalah hubungan kolaborasi yang baik dan informasi yng terpusat dari semua pihak yang terlibat. Semua pihak melakukan tugasnya dengan tepat untuk mencapai satu tujuan yang sama, yaitu memberikan kepuasan kepada konsumen dan mampu mencapai kesejahteraan pada semua pihak yang terlibat pada rantai pasok tuna segar.

Mengkaji rantai pasok tuna segar di likungkungan nelayan dan dramaga transit PPSNZJ dan mengamati hambatan-hambatan dengan menggunakan key succes factor, maka didapatkan beberapa rekomendasi dalam rantai pasok tuna segar dengan tujuan menerapkan praktek terbaik agar mampu mengidentifikasi permasalahan dan memberi solusi dalam mencapai kinerja yng lebih efektif dan efisien. Rekomendasi tersebut diantaranya, optimalisasi peran institusi, pemusatan dan pengembangan sistem informasi, dan kolaborasi yang baik antar pihak, dan kemudahaan akses pembiayaan. Gambar 5 Ilustrasi rekomendasi antar anggota rantai pasok.

Proses bisnis dalam hubungan kolaborasi diarahkan agar menjadi sistem pull. Tujuannya agar tindakan pelayanan yg dilakukan menjadi lebih responsif. Melalaui perencaan penjualan yang jelas serta dengan perencanaan produksi yang matang sehingga mampu mengurangi resiko oprasional seperti tidak adanya produk, bullwhip, kesalahan forecasting, dan resiko pasar. Adapun bentuk gambaran hubungan kolaborasi downstream (nelayan) dengan pihak lain dalam rantai pasok di ilustrasikan pada Gambar 6.

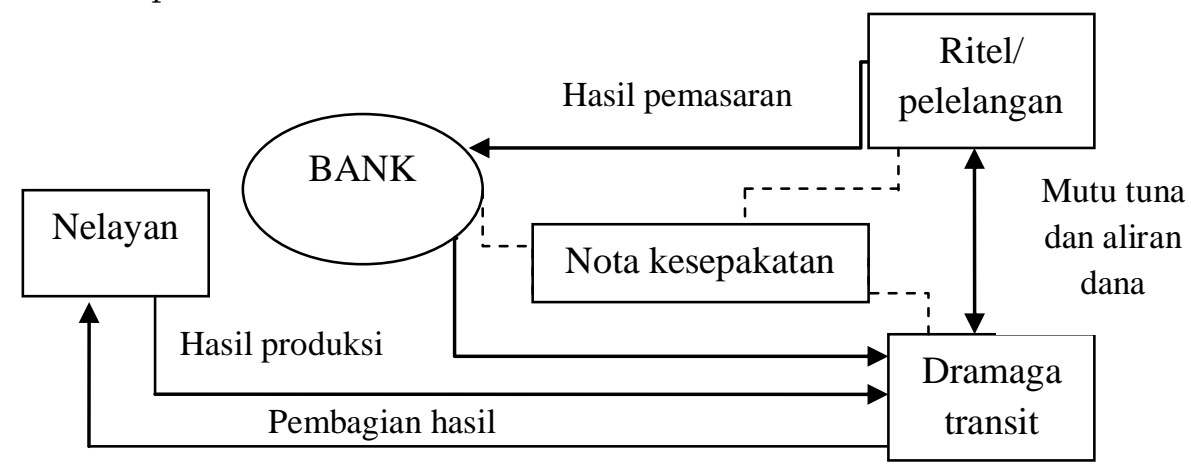

Gambar 6 Hubungan kolaborasi nelayan dengan pihak lain dalam rantai pasok 


\section{Analisa Peningkatan Kinerja Manajemen Rantai Pasok di PPSNZJ}

Pengukuran kinerja rantai pasok tuna segar PPSNZJ menggunakan SCOR dengan cara menilai sejauh mana peningkatan kinerja yang dikehendaki. Penilaian tersebut membutuhkan ukuran kuantitatif yang disebut kartu SCOR disertai metrik-metrik penilainnya. Faktor internal adalah hal-hal yang dihadapi pelabuhan dalam usahanya dalam memenuhi keinginan pasar, sedangkan faktor eksternal adalah hal-hal yang berkaitan dengan keinginan pasar atau pihak ekternal. Kartu SCOR PPSNZJ ditampilkan pada Tabel 1

Kartu SCOR menampilkan jika pembeli dan pihak industri hendak memesan bahan baku HTI unggulan maka harus menunggu selama 90 hari untuk PPSNZJ dan 14 hari. Jumlah yang cukup lama untuk memperoleh bahan baku industri olahan. Selain itu lamanya waktu menunggu (lead time), pembeli sangat beresiko tidak memperoleh pesanannya seperti yang diinginkan apabila sedang musik paceklik. Sebab nilai dari metrik pemenuhan pesanan sempurna, menunjukan bahwa
PPSNZJ mampu memenuhi pesanan pembeli secara sempurna sebesar $75 \%$. Prentase $25 \%$ PPNZJ adalah pesanan yng tidak terpenuhi sama sekali. Jika memesan secara langsung, maka pembeli harus menunggu rata-rata selama 1 hari hingga bunga tersebut diterima kembali oleh pembeli.

Pada metrik flesibilitas rantai pasok atas jika terdapat peningkatan pesanan sebanyak 20 $\%$ dari total permintaan, maka PPSNZJ mampu memenuhinya dalam waktu 97 hingga ikan diterima pembeli. Sedangkan apabila melalaui pembelian secara langsung, PPSNZJ mampu menyediakan dalam waktu 7 hari. Selang waktu 7 hari tersebut adalah periode yang dibutuhkan untuk mendapatkan outsource tambahan HTI unggulan dari nelayan kapal lain. Pembeli HTI unggulan melakukan outsource ke para nelayan di PPSNZJ, namun ketersediaan Ikan dari para nelayanpun tidak dapat dipastikan karena terkendala musim, dan ketidakpastian keberadaan daerah penangkapan ikan dan jumlah ikan yang didapat sehingga ada kemungkinan pembeli

Tabel 1 Kartu SCOR rantai pasok tuna segar PPSNZJ

\begin{tabular}{|c|c|c|c|c|}
\hline & Tinjauan Metrik & \multicolumn{2}{|l|}{ Metrik SCOR Level 1} & Aktual \\
\hline \multirow{7}{*}{ 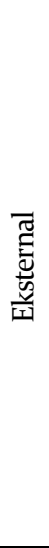 } & Reliabilitas Rantai Pasok & \multicolumn{2}{|c|}{ Pemenuhan Pesanan Sempurna } & $75 \%$ \\
\hline & \multirow{2}{*}{ Rensponsivitas } & \multirow{2}{*}{$\begin{array}{c}\text { Order Fulfillment Lead } \\
\text { Time }\end{array}$} & A & 90 hari \\
\hline & & & $\mathrm{H}$ & 1 hari \\
\hline & \multirow{4}{*}{ Fleksibilitas } & \multirow{2}{*}{$\begin{array}{l}\text { Fleksibilitas Rantai } \\
\text { Pasok Atas }\end{array}$} & A & 97 hari \\
\hline & & & $\mathrm{H}$ & 7 \\
\hline & & \multicolumn{2}{|c|}{ Penyesuaian Rantai Pasok Atas } & $30 \%$ \\
\hline & & \multicolumn{2}{|c|}{ Penyesuaian Rantai Pasok Bawah } & $0 \%$ \\
\hline \multirow{4}{*}{ 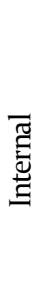 } & \multirow{2}{*}{ Biaya } & $\begin{array}{c}\text { Biaya Total } \\
\text { ManajemenRantaiPa }\end{array}$ & & $25 \%$ \\
\hline & & Biaya Pokok Produ & & $60 \%$ \\
\hline & \multirow{2}{*}{ Aset } & \multicolumn{2}{|l|}{ Siklus Cash-to-cash } & 7 hari \\
\hline & & \multicolumn{2}{|c|}{ Return on SC Fixed Asset } & \\
\hline
\end{tabular}


tidak dapat memenuhi peningkatan pemesanannya.

Pada metrik penyesesuaian rantai pasik atas, PPSNZJ mampu meningkatkan ketersediaan stok ikannya hingga mencapai 30\% dari total kapasitas produksi dalam kurun waktu 30 hari. Jumlah tersebut tergolong cukup baik. Sedangkan metrik penyesuaian rantai pasok bawah memiliki nilai $0 \%$ yang berarti apabila menurunkan kapasitas produksi hingga $0 \%$, maka tidak dikenankan pinalti atau denda biaya.

Pada metrik biaya total manajeman rantai pasok, biaya yang dikeluarkan oleh industri-industri di PPSNZJ sebesar 25\% dari harga jual. Jumlah tersebut relatif tergantung dari kebutuhan masing-masing perusahaan. Harga pokok produk rata-rata sebesar 60\% untuk PPSNZJ bisa jadi beragam di setiap perusahaan tergantung pada standar yang ditetapkan. Namun jika biaya pokok produk terlalu tinggi, maka faktor-faktor inefisiensi sudah seharusnya diidentifikasi.

Peningkatan kinerja manajemen rantai pasok tuna segar perlu memastikan kondisi yang bersangkutan berada dalam posisi yang siap untuk melakukan pengembangan. Analisis SWOT digunakan pada PPSNZJ sehingga dapat disimpulkan bahwa posisi usaha tuna segar di PPSNZJ siap untuk melakukan ekspansi dan pengembangan bisnis. Strategi yang didapatkan berdasarkan pengamatan kondisi rantai pasok terhadap kekuatan (Strength) dan kelemahan (Weakness) untuk menyikapi peluang (Opprtunities) serta ancaman (Treats) (Rangkuti 1998 dalam Marimin 2004). Tabel 2

Tabel 2 Strategi SWOT rantai pasok tuna segar PPSNZJ

\begin{tabular}{|c|c|c|}
\hline \multirow{2}{*}{\begin{tabular}{l}
\multicolumn{1}{c}{ EFAS } \\
(External Strategic Factors \\
Analysis Summary) \\
\end{tabular}} & \multicolumn{2}{|c|}{$\begin{array}{c}\text { IFAS } \\
\text { (Internal Strategic Factors Analysis Summary) }\end{array}$} \\
\hline & $\begin{array}{l}\text { Strength (kekuatan) } \\
\text { 1. Sumber daya ikan tuna } \\
\text { 2. Sarana pelabuhan dan } \\
\text { moda transportasi yang } \\
\text { memadai } \\
\text { 3. Armada penangkapan } \\
\text { memadai } \\
\text { 4. Adanya industri } \\
\text { penanganan dan } \\
\text { pengolahan tuna }\end{array}$ & $\begin{array}{l}\text { Weakness (kelemahan) } \\
\text { 1. Antrian kapal di dramaga } \\
\text { transit yang panjang } \\
\text { 2. Arus informasi yang } \\
\text { kurang terpusat } \\
\text { 3. fasilitas pelidung sinar } \\
\text { matahari kurang } \\
\text { memadai } \\
\text { 4. SDM metode bongkar } \\
\text { muat tuna belum } \\
\text { sepenuhnya mengikuti } \\
\text { standar }\end{array}$ \\
\hline 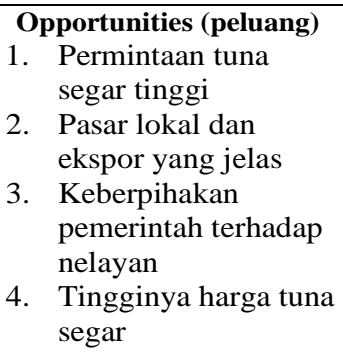 & $\begin{array}{l}\text { Strategi SO } \\
\text { 1. Pengembangan diarahkan } \\
\text { kepada penangkapan tuna } \\
\text { yang berkelanjutan } \\
\text { 2. Invasi pemasaran lokal } \\
\text { dan ekspor }\end{array}$ & $\begin{array}{l}\text { Strategi WO } \\
\text { 1. } \begin{array}{l}\text { Memperat kerjasama } \\
\text { dengan pihak pelelang } \\
\text { dan lembaga keungan } \\
\text { terkait }\end{array} \\
\text { 2. Penerapan standar dan } \\
\text { pelatihan penanganan } \\
\text { tuna segar di Pelabuhan } \\
\text { 3. Optimalisasi dramaga } \\
\text { transit }\end{array}$ \\
\hline \begin{tabular}{ll}
\multicolumn{2}{c}{ Treats (ancaman) } \\
1. \\
IUU Fishing \\
2. \\
Biaya transportasi \\
dan distribusi yang \\
tinggi \\
3. \\
Sistem pembayaran \\
hasil penjualan yang \\
belum efisien \\
4. \\
posisi tawar \\
(bergaining position) \\
nelayan yang rendah
\end{tabular} & $\begin{array}{ll}\text { Strategi ST } \\
\text { 1. } & \text { Mempererat kemitraan } \\
& \text { nelayan dalam rantai pasok } \\
\text { 2. } & \text { Peningkatan pengawasan di } \\
& \text { Pelabuhan dan di Laut } \\
\text { 3. } & \begin{array}{l}\text { Optimalisasi transportasi dan } \\
\text { distribusi }\end{array}\end{array}$ & $\begin{array}{ll}\text { Strategi WT } \\
\text { 1. } & \begin{array}{l}\text { Penguatan posisi tawar } \\
\text { nelayan dengan kebijakan }\end{array} \\
\text { pemerintah } \\
\text { 2. } \\
\text { Membangun sistem } \\
\text { informasi yang aktual, } \\
\text { terpusat, dan mudah } \\
\text { diakses }\end{array}$ \\
\hline
\end{tabular}


Menjelaskan hasil analisis menggunakan metode SWOT.

Hasil analisis SWOT menunjukan bahwa rantai pasok memiliki potensi untuk berkembang. Sumberdaya yang tersedia, tingginya permintaan dan harga tuna menjadikan potensi yang kuat untuk dikembangkan oleh masyarakat, pengusaha, dan pemerintah. Peningkatan kinerja rantai pasok tuna di PPSNZJ diarahkan pada tingkat kepuasan konsumen yang lebih baik, pemenuhan permintaan yang lebih responsif, memperat kemitraan antara nelayan yang berkelanjutan, yang hasilnya akan mendukug ekspansi penjualan memlalui peningkatan kinerja rantai pasok.

\section{KESIMPULAN}

1. Kajian pengelolaan rantai pasok tuna segar menunjukan bahwa pengelolaannya sangat dipengaruhi oleh kualitas tuna yang didaratkan. Perbedaan tersebut menyebabkan segmentasi pasar menjadi dua, yaitu lokal dan ekspor. PPSNZJ mampu meningkatkan ketersediaan stok ikannya hingga mencapai 30\% dari total kapasitas produksi dalam kurun waktu 30 hari. Hal tersebut menjadi modal pengembangan rantai pasok menjadi lebih efisien.

2. Kinerja rantai pasok tuna segar di PPSNZJ masih kurang optimal. Waktu yang dibutuhkan oleh pihak konsumen dan industri (order fullfillment lead time) yang hendak memesan tuna segar maka harus menunggu selama 90 hari. Jumlah yang cukup lama untuk memperoleh bahan baku industri. Selain itu lamanya menunggu (lead time), pembeli sangat beresiko tidak memperoleh pesanannya seperti yang diingaikan apabila sedang musim paceklik.

\section{DAFTAR PUSTAKA}

Castro FR, Suzana SR, Reis SS, Oliveira EN, and Andrio A. 2014. Fishermen's perception of Neotropical otters (Lontra longicaudis) and their ttacks on artisanal fixed fence traps: The case of caiçara communities. Journal of Ocean and Coastal Management. 92(1):19-27.

Chopra S dan P Meindl. 2004. Supply Chain Management: Strategy, Planning, dan Opration. America (US). Pearson Prentice Hall.

[Ditjen PT] Direktorat Jendral Perikanan Tangkap (ID). 2015. Buku Statistik KKP. 1(1): 40-60

Ekinci Y, Ulengin F, Uray N, and Ulengin B. 2014. Analysis of customer lifetime value and marketing expenditure decisions through a Markovian-based model. European Journal of Operational Research. 237(1):278-288.

Indrajit RE dan R Djokopranoto. 2002. Konsep Manajemen Supply Chain Cara Baru Memandang Mata Rantai Penyediaan Barang. Jakarta (ID). Grasindo.

Machfud dan Sahar H. 2002. Analisis Kinerja Sistem Antrian pada Industri Pengolahan Fillet Ikan Beku (Studi Kasus di PT.GTS, Jawa Barat). Jurnal Teknologi Industri Pertanian. 18(2): 118-126.

Makino M, Matsuda H, dan Sakurai Y. 2009. Expanding Fisheries Co-management to Ecosystem-Based Management : A case in the Shiretoko World Natural Heritage Area, Japan. Journal of Matime Policy. 33(2):207-214.

Marimin dan N. Maghfiroh. 2007. Preliminary Country Report, Supply Chains for Perishables Agricultural Products in Indonesia. Fateta, IPB. Bogor

Marimin dan Syafi FN. 2009. Kajian Peningkatan Kinerja Manajemen Rantai Pasok Bunga Krisan. Fateta, IPB. Bogor 
Persaulian B, Aimon H, dan Anis A. 2013. Analisis Konsumsi Masyarakat di Indonesia. Jurnal Kajian Ekonomi. 1(2): 1-23.

[PPSNZJ] Pelabuaha Perikanan Samudra Nizam Zachman Jakarta (ID). 2015. Buku Statistik PPSNZJ. Direktorat Jendral Kementrian Kelautan Perikanan (KKP). 1(1):50-65

Suharso dan Santoso H. 2008. Model Permintaan Yellowfin Segar Indonesia Pasar Jepang. Buletin Ekonomi Perikanan. Volume VIII 2(8):69-81.

Sunoko R and Huang HW. 2014. Indonesia Tuna Fisheries Development and Future strategy. Marine Policy Journal. 43:174-183.

Supriatna A, Hascaryo B, Wisudo SH, Baskoro M, Nikijuluw VPH. 2014. Model Rantai Nilai Pengembangan Perikanan Tuna, Tongkol, dan Cakalang di Indonesia. Masyarakat Pengolahan Hasil Perikanan Indonesia (JPHPI). 17(2): 144-145.

Marimin. 2014. Teknik dan Aplikasi Pengambilan Keputusan Kriteria Majemuk. Jakarta (ID): Grasindo.

Vorst, G.A.J. Van Der. 2006. Performance Measurment in Ari-Food Supply-Chain Networks - An overview. Netherlands. Springer. 